\title{
Genistein enhances TRAIL-induced cancer cell death via inactivation of autophagic flux
}

\author{
UDDIN MD. NAZIM ${ }^{1,2}$ and SANG-YOUEL PARK ${ }^{1,2}$ \\ ${ }^{1}$ Biosafety Research Institute, College of Veterinary Medicine, ${ }^{2}$ Department of Bioactive Material Sciences \\ and Research Center of Bioactive Materials, Chonbuk National University, Jeonju, Jeonbuk 561-756, Republic of Korea
}

Received May 29, 2015; Accepted July 23, 2015

DOI: $10.3892 /$ or.2015.4247

\begin{abstract}
Tumor necrosis factor-related apoptosis-inducing ligand (TRAIL) is a transmembrane cytokine that is a promising anticancer agent as it selectively induces apoptosis in various types of tumor cells. Autophagic flux, which includes the complete process of autophagy, and suppression of autophagic flux has been increasingly recognized as a favorable and novel therapeutic approach for cancer treatment. Here, we showed that genistein, a major isoflavone compound that exerts its anticancer properties by inhibiting tumor cell proliferation, can induce TRAIL-mediated apoptotic cell death in TRAIL-resistant human adenocarcinoma A549 cells. Notably, genistein treatment led to a marked increase in the accumulation of microtubule-associated protein 1 light chain 3 (LC3)-II and p62 protein levels. The combination of genistein and TRAIL increased LC3-II, p62, activated caspase- 3 and activated caspase- 8 accumulation, confirming the inhibition of autophagic flux. Taken together, our results revealed that genistein enhanced TRAIL-induced tumor cell death in TRAIL-resistant A549 adenocarcinoma cells by inhibiting autophagic flux.
\end{abstract}

\section{Introduction}

Tumor necrosis factor-related apoptosis-inducing ligand (TRAIL) is a transmembrane cytokine that is a promising anticancer agent in cancer research (1). TRAIL has the ability to selectively induce apoptosis in a wide range of tumor cells but does not induce toxicity in most normal cells (2). TRAIL also engages the extrinsic apoptotic pathway by binding to the DR4 and DR5 death receptors, which triggers apoptotic signaling (3). The activation of the death receptor recruits Fas-associated death domain protein (FADD) and

Correspondence to: Professor Sang-Youel Park, Biosafety Research Institute, College of Veterinary Medicine, Chonbuk National University, Jeonju, Jeonbuk 561-756, Republic of Korea E-mail: sypark@chonbuk.ac.kr

Key words: genistein, autophagy, tumor necrosis factor-related apoptosis-inducing ligand, lung cancer eventually procaspase- 8 to form the death-inducing signaling complex (DISC), leading to the activation of the caspase cascade (caspase-8, -9, -10 and -3) (4,5). It has been reported that many tumor cells, including human lung adenocarcinoma A549 cells, are resistant to the apoptotic effects of the TRAIL signaling pathway (6).

Genistein, a major isoflavone compound of soybeans and soy products, has been shown to have numerous beneficial effects on diverse cell functions $(7,8)$. Previous studies indicate that genistein exerts anticancer properties that include the inhibition of tumor cell proliferation, enhanced tumor cell differentiation triggering cell cycle arrest, and the induction of apoptosis in some cell types (9-11). Genistein promotes the inhibition of protein tyrosine kinase by competing with ATP for tyrosine kinase domain binding, resulting in a decrease in cancer cell proliferation due to interruption of the tyrosine kinase cascade stimulated by mitogens $(12,13)$. Genistein is also known as an estrogen receptor agonist that can antagonize the multiplication of breast cancer cells due to estradiol exposure (14).

Autophagy is a lysosomal-dependent degradation process induced during starvation, hypoxic conditions, growth factor deprivation, or endoplasmic reticulum stress in addition to other stressors (15). However, autophagy can also incite cell death due to mitophagy, the loss of mitochondrial membrane potential, caspase cascade activation, and finally lysosomal membrane permeabilization (16). Autophagic flux is the complete mechanism of autophagy originating with the fusion of the autophagosome with a lysosome, resulting in degradation and recycling of the cargo (17). Microtubule-associated protein 1 light chain 3 (LC3), which is a ubiquitin-like protein necessary during proteolytic processing, yields a $16-\mathrm{kDa}$ LC3-I protein that conjugates with phosphatidyl ethanolamine to yield a 14-kDa LC3-II form, where LC3-II is used as a marker of complete autophagosome activation (18-20). The p62 protein, also known as sequestosome 1 (SQSTM1), is a ubiquitin-like protein involved in the lysosome-dependent degradation system that directly interacts with LC3-II and degradation in the autophagy process, and inhibition of autophagy leads to increased p62 protein levels $(18,19)$. The role of autophagy in cancer is like a double-edged sword; during tumorigenesis or oncogenesis processes it functions as a mechanism for tumor suppression (21-23) whereas when a tumor is formed, autophagy provides a cell survival advantage 
to resist cell death induced by cancer therapy (24). Recent studies suggest that the pharmacological or genetic inhibition of autophagy increases the conventional effects of chemotherapy (25-27), suggesting that the inhibition of autophagy may be an appropriate and encouraging strategy for cancer treatment. Antimalarial drugs such as chloroquine, which act as autophagy inhibitors, prevent acidification of the lysosome and subsequent autophagosome-lysosome fusion, inducing apoptosis (28-31).

In the present study, we demonstrated that inhibition of autophagic flux by genistein enhanced TRAIL-induced A549 cell death. A549 cells are TRAIL resistant and therefore a single treatment with either genistein or TRAIL did not influence cell death; therefore, we examined whether co-treatment of genistein with TRAIL had a greater effect on A549 lung adenocarcinoma cells. The enhancing effect of genistein on TRAIL-induced cell death in A549 lung adenocarcinoma cells was mediated by inhibition of autophagic flux.

\section{Materials and methods}

Cell culture. Cancer cells originating from A549 lung tumors were obtained from the American Type Culture Collection (Global Bioresource Center, Manassas, VA, USA). The cells were cultured in RPMI-1640 (Gibco-BRL, Grand Island, NY, USA) medium supplemented with $10 \%$ (v/v) fetal bovine serum and antibiotics (100 $\mu \mathrm{g} / \mathrm{ml}$ penicillin-streptomycin). The cell cultures were incubated in an atmosphere containing $5 \% \mathrm{CO}_{2}$ at $37^{\circ} \mathrm{C}$.

Reagents. Recombinant genistein and chloroquine $(20 \mu \mathrm{M})$ were purchased from Sigma-Aldrich (St. Louis, MO, USA). Recombinant TRAIL (100 ng/ml) was purchased from AbFrontier (Geumcheon-gu, Seoul, Korea).

Cell viability tests. A549 cells were plated at $1.0 \times 10^{4}$ cells in 12 -well plates and incubated at $37^{\circ} \mathrm{C}$ for $24 \mathrm{~h}$. The A549 cells were pretreated with genistein in a dose-dependent manner $(0,10,20$ and $40 \mu \mathrm{M})$. After the $12-\mathrm{h}$ genistein pretreatment, recombinant TRAIL (100 $\mathrm{ng} / \mathrm{ml})$ protein was added and co-incubated for $2 \mathrm{~h}$. Additional cells were also pretreated with chloroquine $(20 \mu \mathrm{M})$ for $1 \mathrm{~h}$ followed by genistein treatment. Cell morphology was assessed by images taken under an inverted microscope (Nikon, Japan), and cell viability was determined using the crystal violet staining method. The cells were stained with a staining solution $(0.5 \%$ crystal violet in $30 \%$ ethanol and $3 \%$ formaldehyde) for $10 \mathrm{~min}$ at room temperature, washed four times with phosphate-buffered saline (PBS) and dried. Then, the cells were lysed with a $1 \%$ SDS solution and measured at an absorbance of $550 \mathrm{~nm}$. Cell viability was calculated from the relative dye intensity compared with a control.

Trypan blue exclusion assays. The number of viable cells was determined by trypan blue dye exclusion (Sigma-Aldrich) using microscopy and a hemocytometer. The results are expressed as a percentage relative to the vehicle-treated controls.

Western blot assays. A549 cell lysates were prepared by harvesting cells, washing in cold PBS, and resuspending in a lysis buffer [25 mM HEPES (pH 7.4), 100 mM EDTA, 5 mM $\mathrm{MgCl}_{2}, 0.1 \mathrm{mM}$ DTT and a protease inhibitor mixture] followed by sonication. Proteins (35 $\mu \mathrm{g})$ were separated on a $10-15 \%$ SDS gel and transferred to a nitrocellulose membrane. After a 1-h incubation with a 1:1,000 primary antibody dilution buffer (1\% milk with PBS-Tween), the membranes were developed by enhanced chemiluminescence using a secondary antibody. The antibodies used for immunoblotting were LC3 (Novus Biologicals, Littleton, CO, USA), anti-p62 (Millipore, Milford, MA, USA), cleaved caspase-3 (Cell Signaling Technology, Inc., Danvers, MA, USA), cleaved caspase-8 (BD Pharmingen, San Diego, CA, USA) and $\beta$-actin (Sigma-Aldrich). Images were examined using a Fusion-FX7 imaging system (Vilber Lourmat, Marne-la-Vallée, France).

Immunocytochemistry. The A549 cell line was cultured on glass coverslips and treated with genistein, chloroquine, and/or TRAIL, washed with PBS, and fixed with 3-4\% paraformaldehyde in PBS for $15 \mathrm{~min}$ at room temperature. Cells were then washed twice with ice cold PBS, incubated for $10 \mathrm{~min}$ in PBS containing $0.25 \%$ Triton X-100, and washed in PBS an additional three times for $5 \mathrm{~min}$. The cells were blocked with $1 \%$ bovine serum albumin (BSA) in PBST for $30 \mathrm{~min}$, and then incubated with the primary antibody (anti-p62, diluted in $1 \%$ BSA in PBST) in a humidified chamber for $1 \mathrm{~h}$ at room temperature or overnight at $4^{\circ} \mathrm{C}$. After the primary antibody treatment, the solution was decanted and the cells were washed three times with PBS for $5 \mathrm{~min}$. The cells were then incubated with the secondary antibody in $1 \%$ BSA for $1 \mathrm{~h}$ at room temperature in the dark, which was followed by decanting the secondary antibody solution and washing three times with PBS for $5 \mathrm{~min}$. The cells were then incubated with DAPI for $1 \mathrm{~min}$ and rinsed with PBS. Finally, the cells were mounted with fluorescent mounting medium and visualized via fluorescence microscopy.

Statistical analysis. The unpaired t-test or Welch's correction was used for comparison between the two groups. The one-way analysis of variance (ANOVA) method followed by the TukeyKramer test was used for multiple comparisons. All statistical analyses were performed using GraphPad Prism software. Results were considered significant for values $\mathrm{p}<0.05, \mathrm{p}<0.01$ and $\mathrm{p}<0.001$.

\section{Results}

Genistein enhances TRAIL-induced apoptosis in A549 cells. To investigate the effects of genistein co-treatment on TRAIL-induced apoptosis in A549 lung adenocarcinoma cells, the cells were pretreated with varying genistein concentrations for $12 \mathrm{~h}$ and followed by treatment with TRAIL protein for an additional $2 \mathrm{~h}$. We photographed the cells under light microscopy to investigate cell morphological changes, and cell viability was analyzed using crystal violet and trypan blue exclusion assays. As shown in Fig. 1, a single treatment of genistein and TRAIL did not or only slightly influenced cell viability with no morphological changes compared to the control A549 cells; however, combination treatment of TRAIL and the indicated doses of genistein significantly decreased cell viability compared to genistein and TRAIL treatment 
A

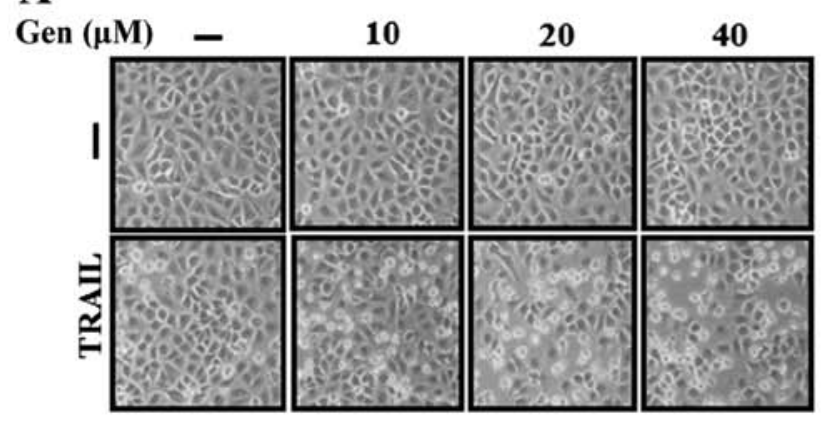

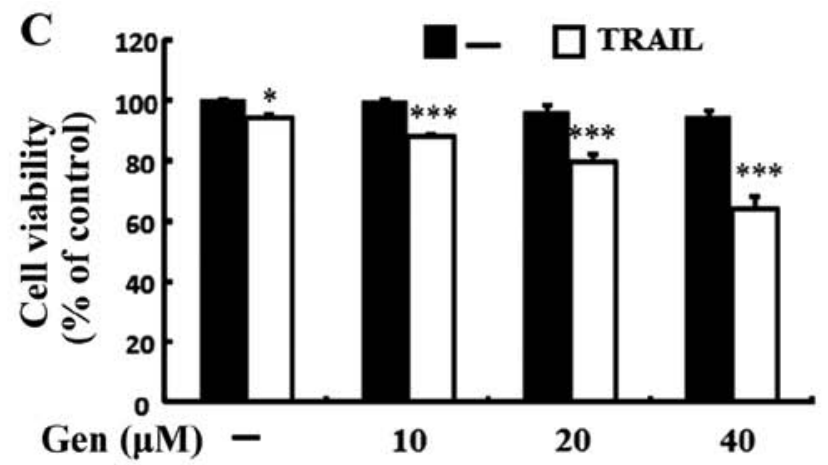

B

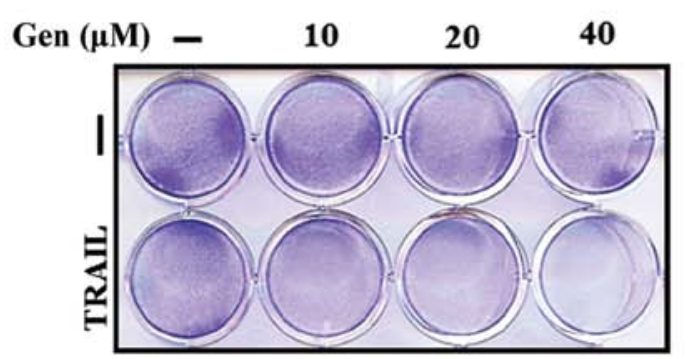

D

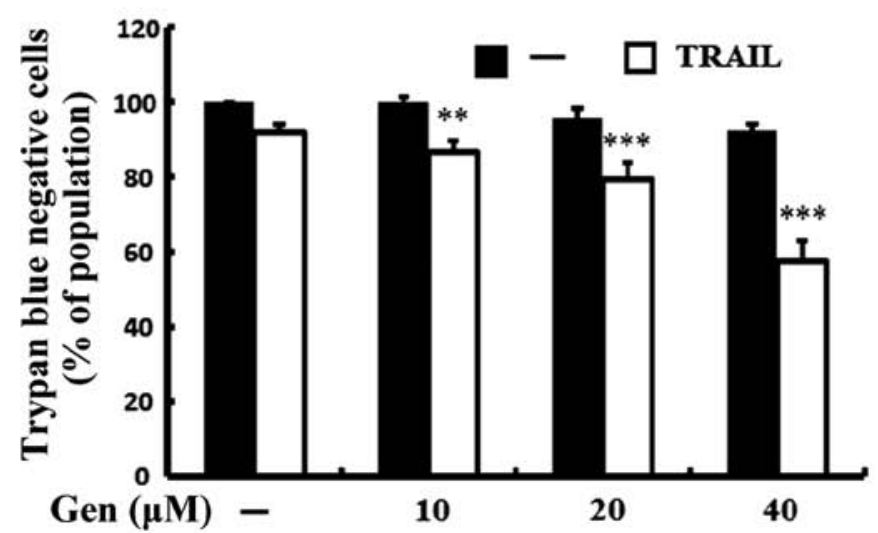

Figure 1. Genistein enhances TRAIL-induced apoptosis in A549 cells. A549 cells were pretreated with genistein in a dose-dependent manner (0, 10 , 20 and $40 \mu \mathrm{M}$ ) for $12 \mathrm{~h}$ and were then treated with $100 \mathrm{ng} / \mathrm{ml}$ TRAIL protein for an additional $2 \mathrm{~h}$. (A) Cell morphology was captured under light microscopy (magnification, x100), and (B) cell viability was assessed by the crystal violet assay. (C) The bar graph indicates the average density of crystal violet dye. (D) The treated cells were also assessed by trypan blue dye exclusion assays. ${ }^{*} \mathrm{P}<0.05,{ }^{* *} \mathrm{P}<0.01$ and ${ }^{* * *} \mathrm{P}<0.001$; significant differences between the control and each treatment group. Gen, genistein; TRAIL, tumor necrosis factor-related apoptosis-inducing ligand.

alone. Cell morphology also supported this enhanced effect of genistein, showing that the combination of TRAIL and genistein treatment enhanced apoptotic cell death compared with that of genistein or TRAIL treatment alone (Fig. 1A). However, TRAIL and genistein co-treatment reduced cell viability and significantly increased apoptotic cell death in the A549 cells (Fig. 1B-D). These results indicate that genistein significantly increased TRAIL-induced apoptotic cell death in the TRAIL-resistant A549 cells.

Genistein inhibits autophagic flux in lung adenocarcinoma cells. To investigate the effect of genistein on autophagic flux in A549 cells, the cells were pretreated with varying genistein concentrations for $12 \mathrm{~h}$ followed by treatment with TRAIL protein for an additional $2 \mathrm{~h}$. Whole cell lysates were subjected to western blot analysis to determine changes in LC3-II, p62, activated caspase-3, and activated caspase-8. The production level of p62 and the conversion of LC3-I to LC3-II were increased after genistein treatment in a dose-dependent manner (Fig. 2A). The combined TRAIL and genistein treatment enhanced LC3-II and p62 protein levels compared with those of genistein or TRAIL treatment alone. These results were also confirmed by the presence of the intracellular apoptosis indicators activated caspase- 3 and activated caspase- 8 (Fig. 2B). The expression levels of TRAIL receptors such as DR4 and DR5 were not changed by treatment with genistein alone or by a combination of genistein and TRAIL in the A549 cells (data not shown). The immunocytochemistry results showed that co-treatment of genistein with TRAIL enhanced p62 protein levels compared to those of genistein or TRAIL treatment alone (Fig. 2C). These results indicate that genistein alone or combined treatment with TRAIL and genistein inhibits autophagy flux in A549 cells.

Genistein enhances TRAIL-induced lung cancer cell death by inhibition of autophagic flux. We used chloroquine, which acts as an autophagy inhibitor by preventing acidification of the lysosome, to investigate the effect of genistein-mediated enhancement of TRAIL-induced cell death in A549 lung adenocarcinoma cells. The cells were pretreated with the indicated genistein doses for $12 \mathrm{~h}$ and then treated with TRAIL protein for an additional $2 \mathrm{~h}$. Additional cells were also pretreated with chloroquine for $1 \mathrm{~h}$ followed by genistein treatment. We photographed the cells under light microscopy to investigate morphological changes, and cell viability was analyzed using crystal violet and trypan blue exclusion assays. As shown in Fig. 3, treatment of A549 cells with either TRAIL or genistein alone did not or only slightly influenced cell death and no morphological changes were identified compared to the control. After combined treatment with TRAIL and chloroquine, cell death was strongly enhanced. Cell morphology results also supported this enhanced cell death effect by TRAIL and chloroquine compared to that of genistein or TRAIL treatment alone (Fig. 3A). The combined 
A

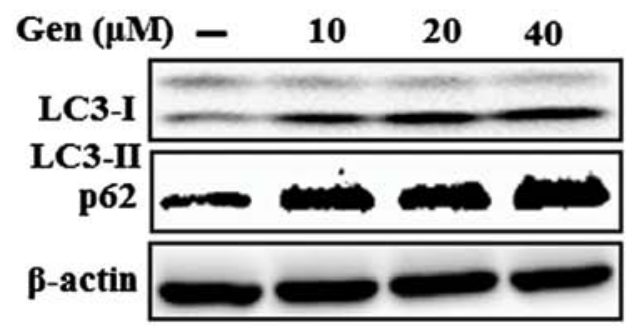

B

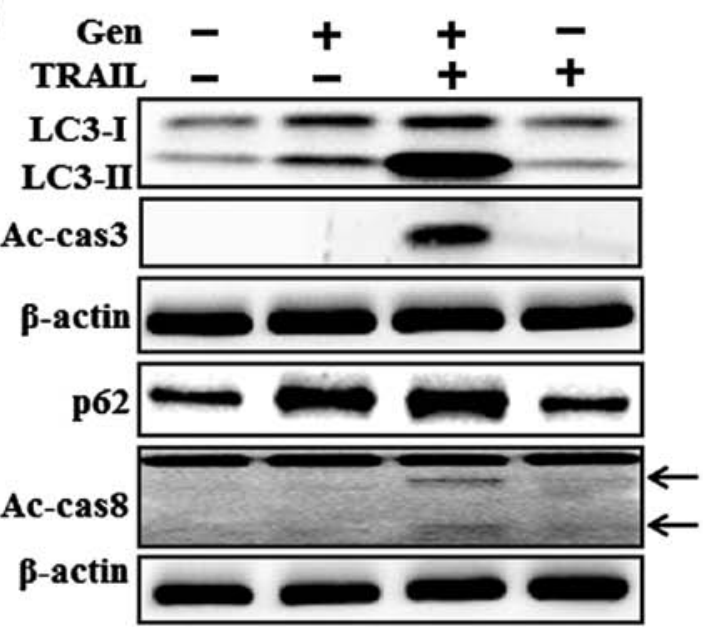

C
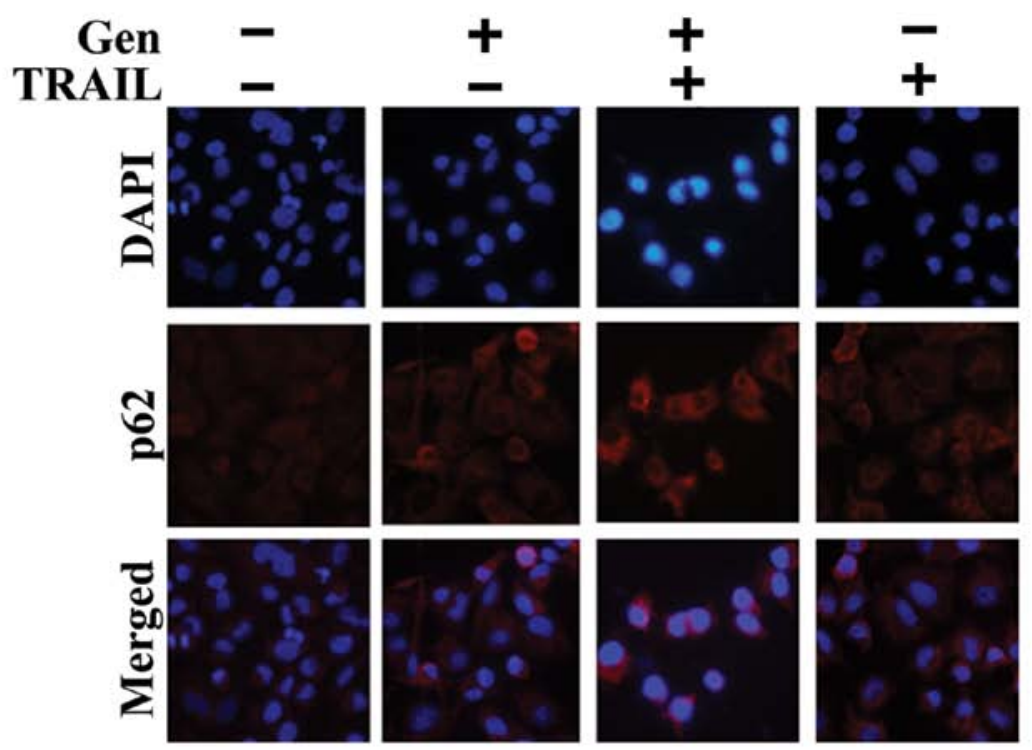

Figure 2. Genistein inhibits autophagic flux in lung adenocarcinoma cells. (A) A549 adenocarcinoma cells were pretreated with genistein in a dose-dependent manner $(0,10,20$ and $40 \mu \mathrm{M})$ for $12 \mathrm{~h}$. The cells were harvested and analyzed by western blotting to determine LC3-II and p62 production levels. A549 cells were pre-treated with genistein $(40 \mu \mathrm{M})$ for $12 \mathrm{~h}$ and then exposed to $100 \mathrm{ng} / \mathrm{ml}$ TRAIL for an additional $2 \mathrm{~h}$. (B) Western blot analyses were performed to determine LC3-II, p62, Ac-cas3 and Ac-cas8 production levels. (C) Representative immunocytochemistry was implemented in A549 cells after co-treatment with genistein (12 h) and 100 ng/ml TRAIL (2 h). Gen, genistein; Ac-cas3, activated caspase-3; Ac-cas8, activated caspase-8; TRAIL, tumor necrosis factorrelated apoptosis-inducing ligand.

treatment of chloroquine and TRAIL reduced cell viability and significantly increased cell death in the A549 lung cancer cells (Fig. 3B-D). These results indicate that genistein-mediated enhanced TRAIL-induced cell death was due to the inhibition of autophagic flux.

Genistein-mediated enhancement of the TRAIL-induced apoptotic pathway by inhibition of autophagic flux. We investigated the effect of genistein-mediated enhancement of the TRAIL-induced apoptotic pathway by inhibiting autophagic flux with chloroquine, which acts as an autophagy inhibitor. The cells were pretreated with the indicated doses of genistein for $12 \mathrm{~h}$ followed by treatment with TRAIL protein for an additional $2 \mathrm{~h}$. Additional cells were also pretreated with chloroquine $(20 \mu \mathrm{M})$ for $1 \mathrm{~h}$ followed by genistein treatment. Whole cell lysates were subjected to western blot analysis to determine changes in LC3-II, p62, activated caspase- 3 and activated caspase- 8 protein levels. The genistein and TRAIL co-treatment, and the combined treatment of TRAIL and chloroquine, resulted in increased LC3-II and p62 protein levels relative to that of chloroquine or TRAIL treatment alone, confirming that genistein inhibited autophagic flux in the A549 cells (Fig. 4A). Chloroquine and TRAIL co-treatment inhibited cell viability and significantly enhanced apoptotic cell death in the A549 cells. These results were confirmed by the presence of intracellular apoptosis indicator activated caspase-3 (Fig. 4B) and there was no clear difference in activated caspase- 8 expression since only TRAIL treatment slightly induced activated caspase- 8 expression compared to co-treatment of TRAIL and chloroquine but was not statistically significant. The immunocytochemistry results showed that the TRAIL and chloroquine combined treatment increased p62 levels compared to those of chloroquine or TRAIL treatment alone (Fig. 4C). These results indicate that the genistein-enhanced TRAIL-induced apoptotic pathway was due to inhibition of autophagic flux.

\section{Discussion}

The purpose of the present study was to investigate the function of genistein and co-treatment of genistein and TRAIL on A549 human adenocarcinoma cells. The results suggest that genistein enhanced TRAIL-induced tumor cell death in A549 cells by inhibition of autophagic flux.

TRAIL, also known as Apo2L, may be a safe and potent biological agent that can be applied for cancer therapy in humans. It has gained huge interest in medical science as it can specifically induce cancer cells, transformed cells, and virus-infected cells to undergo apoptosis without displaying any toxicity in normal cells (32-36). However, the efficacy and mode of action for this effective therapeutic agent are still being investigated. Genistein (4',5,7-trihydroxyisoflavone), commonly found in soy products, has been used as an alternative hormone replacement therapy and has a lower risk 
$\mathbf{A}$

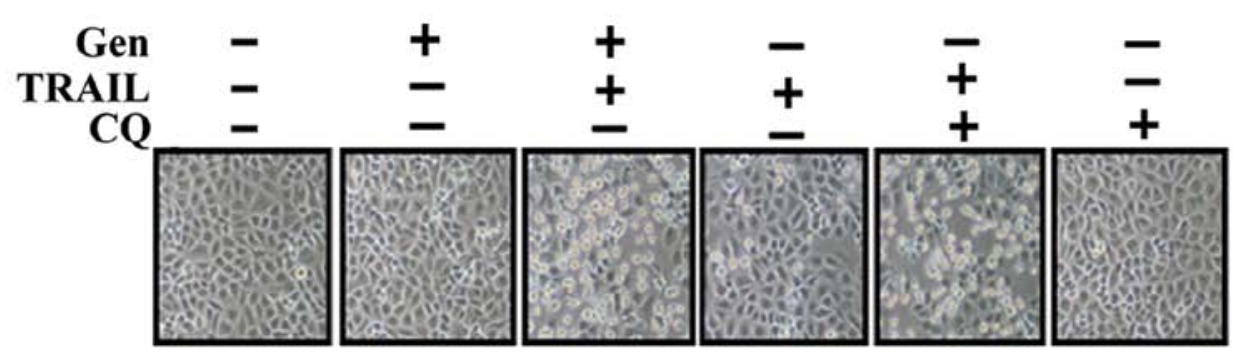

B

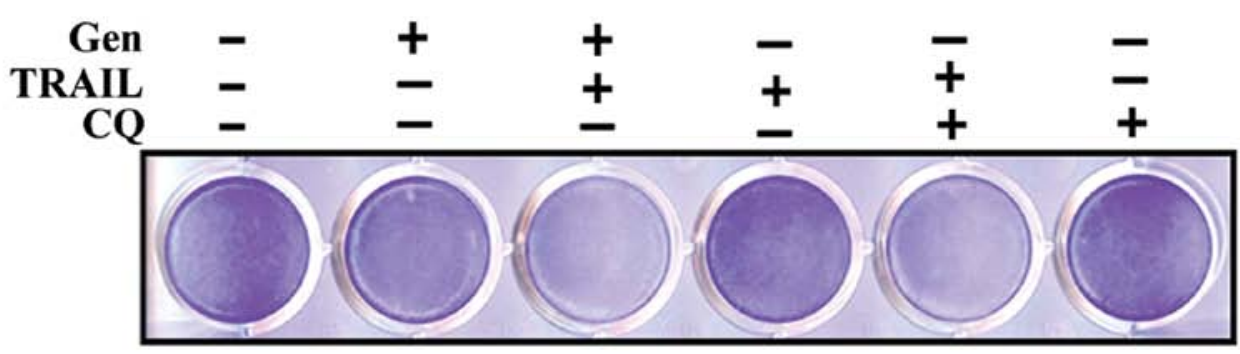

C

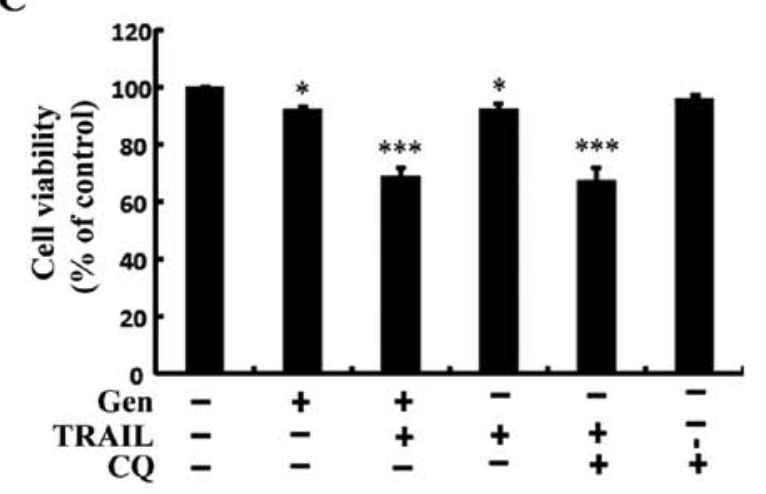

D

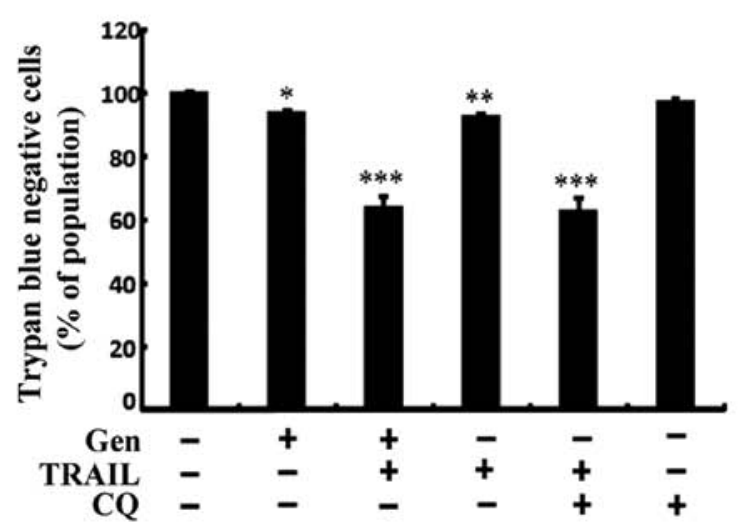

Figure 3. Genistein enhances TRAIL-induced lung cancer cell death by inhibition of autophagic flux. A549 adenocarcinoma cells were pretreated with genistein $(40 \mu \mathrm{M})$ for $12 \mathrm{~h}$ and then treated with $100 \mathrm{ng} / \mathrm{ml}$ TRAIL protein for an additional $2 \mathrm{~h}$. Additional cells were also pretreated with chloroquine for $1 \mathrm{~h}$ followed by genistein treatment. (A) Cell morphology was captured under light microscopy (magnification, x100). (B) Cell viability was measured by the crystal violet assay. (C) The bar graph indicates average density of crystal violet dye. (D) The treated cells were also measured by trypan blue dye exclusion assays. ${ }^{*} \mathrm{P}<0.05,{ }^{* *} \mathrm{P}<0.01$ and ${ }^{* * *} \mathrm{P}<0.001$; significant differences between the control and each treatment group. Gen, genistein; TRAIL, tumor necrosis factorrelated apoptosis-inducing ligand; $\mathrm{CQ}$, chloroquine.

of cancer and neurodegenerative diseases (37). It has been reported that genistein enhances the induction of apoptosis by chemotherapeutic agents in several types of cancer cells $(38,39)$. Autophagic flux is the complete mechanism of autophagy by which cytoplasmic components are recruited to lysosomes for degradation $(40,41)$. Anti-rheumatoid arthritis drugs, such as chloroquine, have been shown to disrupt autophagy in clinical trials of cancer therapy (42).

Most primary tumor cell lines and a range of patientcreated cancer cell lines ultimately become resistant to the apoptotic effects of TRAIL (43). Jin et al (6) showed that lung adenocarcinoma A549 cells are resistant to cell death by TRAIL. We also observed in our present study that a single treatment of genistein or TRAIL alone did not or only slightly induced cell death in A549 adenocarcinoma cells. However, the combined treatment of genistein and TRAIL strongly induced cell death in the A549 cells (Fig. 1). This evidence suggests that genistein, which acts as anticancer agent in combination with TRAIL, can be used to sensitize TRAIL-mediated apoptosis in TRAIL-resistant A549 cells. Some reports have shown that genistein induces autophagy and also initiates apoptosis in ovarian cancer cells (44). However, our results indicate that treatment with varying concentrations of genistein alone resulted in a dose-dependent increase in LC3-II and p62 levels in A549 adenocarcinoma cells. The combined TRAIL and genistein treatment enhanced LC3-II, p62, activated caspase-3, and activated caspase- 8 protein production levels compared to the control by inhibiting autophagic flux (Fig. 2). Recently, researchers have shown that co-treatment of genistein and TRAIL inhibited pancreatic cancer cell growth (45) and enhanced TRAIL-mediated apoptosis in lung A549 cells through 

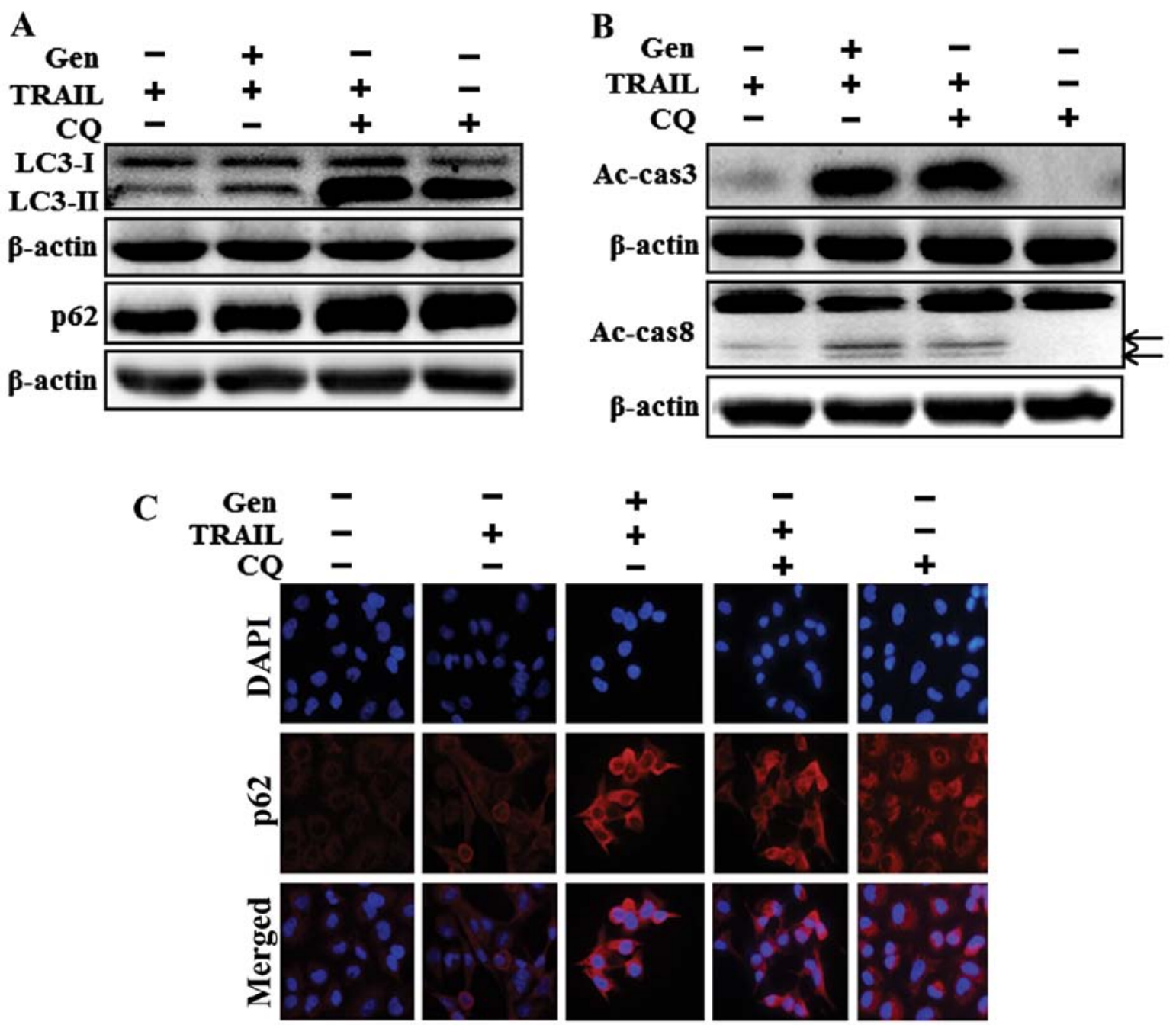

Figure 4. Genistein-mediated enhancement of the TRAIL-induced apoptotic pathway by inhibiting autophagy flux. A549 cells were pretreated with genistein $(40 \mu \mathrm{M})$ for $12 \mathrm{~h}$ and then treated with $100 \mathrm{ng} / \mathrm{ml}$ TRAIL protein for an additional $2 \mathrm{~h}$. Additional cells were also pretreated with chloroquine for $1 \mathrm{~h}$ followed by genistein treatment. (A) The cells were harvested and analyzed by western blot analysis to determine LC3-II and p62 production levels. (B) Western blot analysis was also performed to determine Ac-cas3 and Ac-cas8 production levels. (C) Representative immunocytochemistry was implemented in A549 cells after co-treatment with chloroquine $(1 \mathrm{~h})$, genistein $(12 \mathrm{~h})$ and $100 \mathrm{ng} / \mathrm{ml}$ TRAIL $(2 \mathrm{~h})$. Gen, genistein; TRAIL, tumor necrosis factor-related apoptosis-inducing ligand; CQ, chloroquine; Ac-cas3, activated caspase-3; Ac-cas8, activated caspase-8.

regulation of the AKT pathway (46). Pharmacological or genetic inhibition of autophagy induces cell death in various types of cancer cells, and we investigated the sensitivity of A549 cell proliferation to pharmacological inhibition of autophagy with chloroquine. Co-treatment with genistein and TRAIL increased LC3-II, p62, activated caspase-3 and activated caspase- 8 production levels. Furthermore, TR AIL and chloroquine combined treatment increased LC3-II and p62 levels compared to those of chloroquine or TRAIL alone. These results were confirmed by increased levels of the intracellular apoptosis indicators activated caspase- 3 and activated caspase-8 (Figs. 3 and 4).

In conclusion, we report that genistein enhanced apoptosis in A549 cells by inhibition of autophagic flux. In addition, combination treatment with genistein and TRAIL strongly enhanced apoptosis in TRAIL-resistant A549 cells, suggesting that genistein enhances TRAIL-induced tumor cell death in TRAIL-resistant A549 adenocarcinoma cells by inhibition of autophagic flux.

\section{Acknowledgements}

This study was supported by a grant from the National Research Foundation of Korea (NRF), funded by the Korean Government (MISP) (no. 2013R1A4A1069486).

\section{References}

1. Ashkenazi A, Pai RC, Fong S, Leung S, Lawrence DA, Marsters SA, Blackie C, Chang L, McMurtrey AE, Hebert A, et al: Safety and antitumor activity of recombinant soluble Apo2 ligand. J Clin Invest 104: 155-162, 1999.

2. Bellail AC, Qi L, Mulligan P, Chhabra V and Hao C: TRAIL agonists on clinical trials for cancer therapy: The promises and the challenges. Rev Recent Clin Trials 4: 34-41, 2009.

3. Wang S and El-Deiry WS: TRAIL and apoptosis induction by TNF-family death receptors. Oncogene 22: 8628-8633, 2003.

4. Gonzalvez F and Ashkenazi A: New insights into apoptosis signaling by Apo2L/TRAIL. Oncogene 29: 4752-4765, 2010.

5. Johnstone RW, Frew AJ and Smyth MJ: The TRAIL apoptotic pathway in cancer onset, progression and therapy. Nat Rev Cancer 8: 782-798, 2008. 
6. Jin CY, Park C, Hwang HJ, Kim GY, Choi BT, Kim WJ and Choi YH: Naringenin up-regulates the expression of death receptor 5 and enhances TRAIL-induced apoptosis in human lung cancer A549 cells. Mol Nutr Food Res 55: 300-309, 2011.

7. Kang JL, Lee HW, Kim HJ, Lee HS, Castranova V, Lim CM and Koh Y: Inhibition of SRC tyrosine kinases suppresses activation of nuclear factor-kappaB, and serine and tyrosine phosphorylation of IkappaB-alpha in lipopolysaccharide-stimulated raw 264.7 macrophages. J Toxicol Environ Health A 68: 1643-1662, 2005.

8. Ravindranath $\mathrm{MH}$, Muthugounder S, Presser $\mathrm{N}$ and Viswanathan S: Anticancer therapeutic potential of soy isoflavone, genistein. Adv Exp Med Biol 546: 121-165, 2004.

9. Choi YH, Zhang L, Lee WH and Park KY: Genistein-induced $\mathrm{G} 2 / \mathrm{M}$ arrest is associated with the inhibition of cyclin B1 and the induction of $\mathrm{p} 21$ in human breast carcinoma cells. Int J Oncol 13 391-396, 1998.

10. Choi YH, Lee WH, Park KY and Zhang L: p53-independent induction of p21 (WAF1/CIP1), reduction of cyclin B1 and G2/M arrest by the isoflavone genistein in human prostate carcinoma cells. Jpn J Cancer Res 91: 164-173, 2000.

11. Sarkar FH, Adsule S, Padhye S, Kulkarni S and Li Y: The role of genistein and synthetic derivatives of isoflavone in cancer prevention and therapy. Mini Rev Med Chem 6: 401-407, 2006.

12. Shao ZM, Wu J, Shen ZZ and Barsky SH: Genistein exerts multiple suppressive effects on human breast carcinoma cells. Cancer Res 58: 4851-4857, 1998.

13. Hoffman R: Potent inhibition of breast cancer cell lines by the isoflavonoid kievitone: Comparison with genistein. Biochem Biophys Res Commun 211: 600-606, 1995.

14. Peterson G and Barnes S: Genistein inhibits both estrogen and growth factor-stimulated proliferation of human breast cancer cells. Cell Growth Differ 7: 1345-1351, 1996.

15. Kourtis N and Tavernarakis N: Autophagy and cell death in model organisms. Cell Death Differ 16: 21-30, 2009.

16. Kroemer $G$ and Jäättelä $M$ : Lysosomes and autophagy in cell death control. Nat Rev Cancer 5: 886-897, 2005.

17. Mizushima N: Autophagy: Process and function. Genes Dev 21: 2861-2873, 2007.

18. Klionsky DJ, Abeliovich H, Agostinis P, Agrawal DK, Aliev G, Askew DS, Baba M, Baehrecke EH, Bahr BA, Ballabio A, et al: Guidelines for the use and interpretation of assays for monitoring autophagy in higher eukaryotes. Autophagy 4: 151-175, 2008

19. Mizushima N and Yoshimori T: How to interpret LC3 immunoblotting. Autophagy 3: 542-545, 2007.

20. Mizushima N, Yoshimori T and Levine B: Methods in mammalian autophagy research. Cell 140: 313-326, 2010.

21. Degenhardt K, Mathew R, Beaudoin B, Bray K, Anderson D, Chen G, Mukherjee C, Shi Y, Gélinas C, Fan Y, et al: Autophagy promotes tumor cell survival and restricts necrosis, inflammation, and tumorigenesis. Cancer Cell 10: 51-64, 2006.

22. Karantza-Wadsworth V, Patel S, Kravchuk O, Chen G, Mathew R, Jin S and White E: Autophagy mitigates metabolic stress and genome damage in mammary tumorigenesis. Genes Dev 21 $1621-1635,2007$.

23. Mathew R, Karantza-Wadsworth V and White E: Role of autophagy in cancer. Nat Rev Cancer 7: 961-967, 2007.

24. Chen N and Debnath J: Autophagy and tumorigenesis. FEBS Lett 584: 1427-1435, 2010.

25. Apel A, Herr I, Schwarz H, Rodemann HP and Mayer A: Blocked autophagy sensitizes resistant carcinoma cells to radiation therapy. Cancer Res 68: 1485-1494, 2008.

26. Carew JS, Espitia CM, Esquivel JA II, Mahalingam D, Kelly KR, Reddy G, Giles FJ and Nawrocki ST: Lucanthone is a nove inhibitor of autophagy that induces cathepsin D-mediated apoptosis. J Biol Chem 286: 6602-6613, 2011.

27. Boya P, González-Polo RA, Casares N, Perfettini JL, Dessen P, Larochette N, Métivier D, Meley D, Souquere S, Yoshimori T, et al: Inhibition of macroautophagy triggers apoptosis. Mol Cell Biol 25: 1025-1040, 2005
28. Poole B and Ohkuma S: Effect of weak bases on the intralysosomal $\mathrm{pH}$ in mouse peritoneal macrophages. J Cell Biol 90 665-669, 1981.

29. Fan C, Wang W, Zhao B, Zhang S and Miao J: Chloroquine inhibits cell growth and induces cell death in A549 lung cancer cells. Bioorg Med Chem 14: 3218-3222, 2006

30. Jiang PD, Zhao YL, Deng XQ, Mao YQ, Shi W, Tang QQ, Li ZG, Zheng YZ, Yang SY and Wei YQ: Antitumor and antimetastatic activities of chloroquine diphosphate in a murine model of breast cancer. Biomed Pharmacother 64: 609-614, 2010.

31. Yoon YH, Cho KS, Hwang JJ, Lee SJ, Choi JA and Koh JY: Induction of lysosomal dilatation, arrested autophagy, and cell death by chloroquine in cultured ARPE-19 cells. Invest Ophthalmol Vis Sci 51: 6030-6037, 2010.

32. Van Geelen CM, de Vries EG and de Jong S: Lessons from TRAIL-resistance mechanisms in colorectal cancer cells: Paving the road to patient-tailored therapy. Drug Resist Updat 7: 345-358, 2004.

33. Srivastava RK: TRAIL/Apo-2L: Mechanisms and clinical applications in cancer. Neoplasia 3: 535-546, 2001.

34. Shankar S and Srivastava RK: Enhancement of therapeutic potential of TRAIL by cancer chemotherapy and irradiation: Mechanisms and clinical implications. Drug Resist Updat 7: 139-156, 2004.

35. LeBlanc H, Lawrence D, Varfolomeev E, Totpal K, Morlan J, Schow P, Fong S, Schwall R, Sinicropi D and Ashkenazi A: Tumor-cell resistance to death receptor-induced apoptosis through mutational inactivation of the proapoptotic Bcl-2 homolog Bax. Nat Med 8: 274-281, 2002.

36. Kim H, Kim EH, Eom YW, Kim WH, Kwon TK, Lee SJ and Choi KS: Sulforaphane sensitizes tumor necrosis factor-related apoptosis-inducing ligand (TRAIL)-resistant hepatoma cells to TRAIL-induced apoptosis through reactive oxygen species-mediated up-regulation of DR5. Cancer Res 66: $1740-1750,2006$

37. Gencel VB, Benjamin MM, Bahou SN and Khalil RA: Vascular effects of phytoestrogens and alternative menopausal hormone therapy in cardiovascular disease. Mini Rev Med Chem 12: 149-174, 2012

38. Banerjee S, Li Y, Wang Z and Sarkar FH: Multi-targeted therapy of cancer by genistein. Cancer Lett 269: 226-242, 2008.

39. Sarkar FH and Li Y: Using chemopreventive agents to enhance the efficacy of cancer therapy. Cancer Res 66: 3347-3350, 2006.

40. Codogno P and Meijer AJ: Autophagy and signaling: Their role in cell survival and cell death. Cell Death Differ 12 (Suppl 2): 1509-1518, 2005

41. Klionsky DJ and Emr SD: Autophagy as a regulated pathway of cellular degradation. Science 290: 1717-1721, 2000.

42. Sotelo J, Briceño E and López-González MA: Adding chloroquine to conventional treatment for glioblastoma multiforme: A randomized, double-blind, placebo-controlled trial. Ann Intern Med 144: 337-343, 2006

43. Stegehuis JH, de Wilt LH, de Vries EG, Groen HJ, de Jong S and Kruyt FA: TRAIL receptor targeting therapies for non-small cell lung cancer: Current status and perspectives. Drug Resist Updat 13: 2-15, 2010.

44. Gossner G, Choi M, Tan L, Fogoros S, Griffith KA, Kuenker M and Liu JR: Genistein-induced apoptosis and autophagocytosis in ovarian cancer cells. Gynecol Oncol 105: 23-30, 2007.

45. Nozawa F, Itami A, Saruc M, Kim M, Standop J, Picha KS, Cowan KH and Pour PM: The combination of tumor necrosis factor-related apoptosis-inducing ligand (TRAIL/Apo2L) and genistein is effective in inhibiting pancreatic cancer growth Pancreas 29: 45-52, 2004.

46. Park SY and Seol DW: Regulation of Akt by EGF-R inhibitors, a possible mechanism of EGF-R inhibitor-enhanced TRAIL-induced apoptosis. Biochem Biophys Res Commun 295: $515-518,2002$ 